\title{
Towards Enhanced Process and Tools for Aircraft Systems Assessments during very Early Design Phase
}

\author{
Eric Thomas ${ }^{1}$ Olivier Thomas ${ }^{1} \quad$ Raphael Bianconi $^{1} \quad$ Matthieu Crespo $^{2} \quad$ Julien Daumas $^{2}$ \\ ${ }^{1}$ Dassault Aviation, France, \{eric.thomas, olivier.thomas, raphael.bianconi\}@dassault-aviation.com, \\ ${ }^{2}$ Liebherr Aerospace, France, \{matthieu.crespo, julien.daumas\} @liebherr.com
}

\begin{abstract}
This paper deals with an improved process for early to detailed design phases of complex Aircraft systems. It is based on experience of Dassault Aviation (DASSAV) and Liebherr Aerospace Toulouse (LTS) in aircraft system design, and on works carried out within several R\&D projects, in particular within current FP7 TOICA project (Thermal Overall Integrated Conception of Aircraft), where new process are developed to tackle assessments of architectures composed of many heterogeneous and interconnected sub-systems using simulation. This new process that will be described in this paper involves open standards like Modelica and FMI.
\end{abstract}

Keywords: Collaborative process, System engineering, MBSE, multi-levels simulation, PLM/SLM integration

\section{Introduction}

Aircraft vehicle systems are typical examples of complex systems, composed of many sub-systems provided by several companies, which overall represent a set of thousands of equipments with many interactions between them. These systems must meet numerous performance and safety requirements.

Architectures trade-offs require different kinds of analysis, in particular behavioural assessments. The purpose of this paper is to define vehicle system architectures, investigate the current performance assessment process and propose an improved process based on models exchanges and simulations, applicable during preliminary design phases like RFI (Request For Information) or RFP (Request for Proposal):

The article is structured as follows:

- Section 2 briefly presents aircraft vehicle systems architecture and their representations.

- Section 3 analyses the current design process.

- Section 4 explains current issues in air system design and solutions developed within the project FP7 TOICA

- Section 5 presents solution used within the project and the challenges ahead to get a full and efficient set of tools and processes for future airplane designs

The analysis will start by the description of the current process for architectures assessments, by defining:
- The content and representation of an architecture

- The required activities to assess architectures during the different design phases.

\section{Aircraft architectures}

The Aircraft systems architectures are generally managed using tree views (product break-down ...) and 2D views as represented in fig.1. They allow to describe the system by hierachical decomposition within different levels (e.g. aircrafts, systems, subsystems ... components/devices ...) represented here as boxes with connections between them (Internal Block Diagram according to SysML).

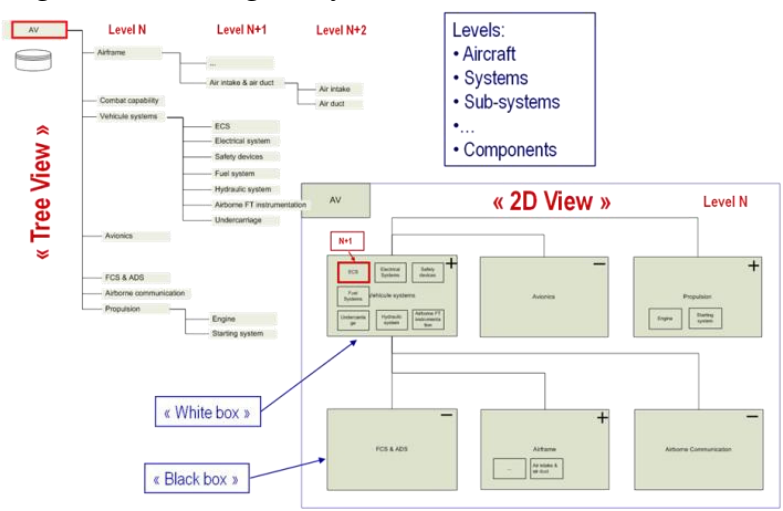

Figure 1. Typical Aircraft (A/C) Logical Architecture

This global system/product is developped with many partners for which access rights to the whole aircraft definition, and associated models, can be restricted and depend on roles of users (e.g. Dassault Aviation Architects, Designers, partner designers ...) They have only access to items they are responsible and, within limits, to the borders and particular information of other surrounding systems. So several systems could appear for users as "white boxes", with complete access to all information, "black boxes" or as "grey boxes", with only access to several published information according to user's role. And this status could vary along the time and the design phases.

These representations are very useful to describe the global architecture and for the navigation within it. For example, if the "vehicle system" node is selected in the tree view, it is possible to get more information on elements of this layer and to focus on sub parts to get more detailed information, as represented in the following figure 2 . 


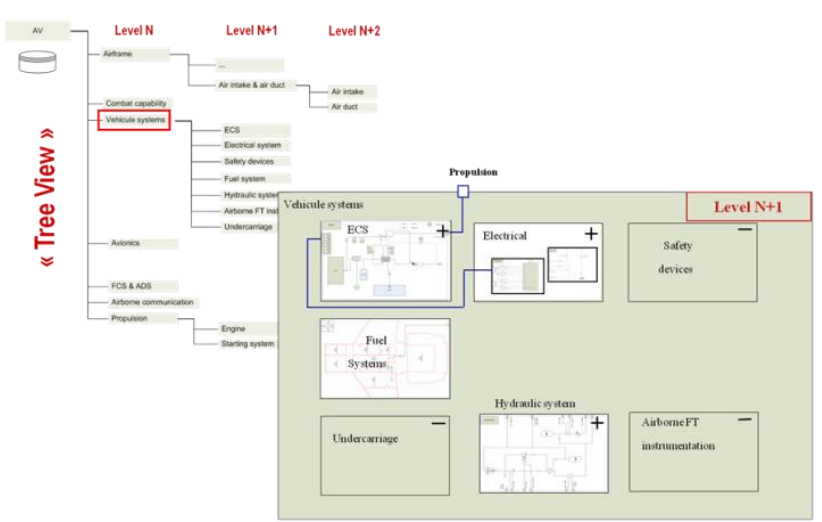

Figure 2. Typical Vehicle Systems Logical Architecture

In addition, for design specialists, elements of the systems could be represented using standards (e.g. symbols) or with not standard representations (e.g. product images ...) to quickly identify main functions of components. In this way, several typical subsystems are represented below with different technical representations and layout. And, according to the previous hirarchical representation, their below to differents levels, here layers $\mathrm{N}, \mathrm{N}+1$ et $\mathrm{N}+2$.

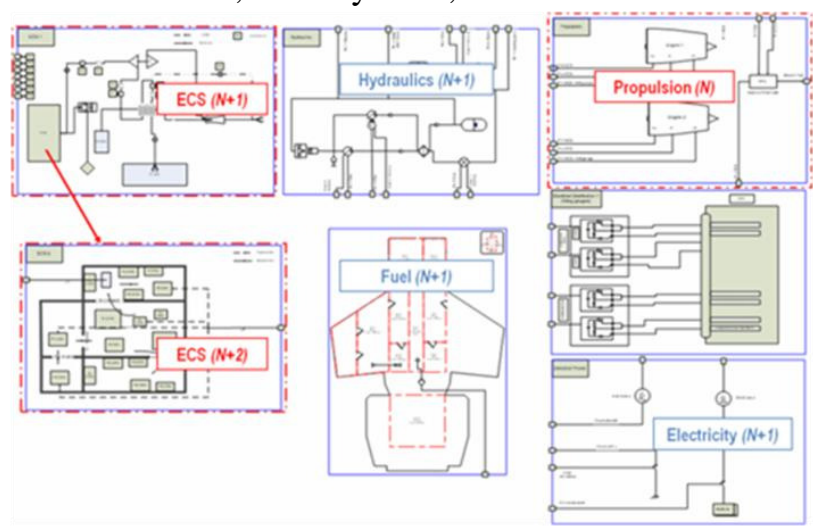

Figure 3. Sub-systems and associated components at different levels (very simplified views)

In fact, representations of complex systems with multiple viewpoints already exist and we can find associated tools to manage them in association with the digital Mock-Up (DMU) to manage them in collaborative context with IP (Intellectual Properties).

But, because of the large amount of requirements at aircraft level and attached to each sub-system, assessments and trade-offs between such architectures are not easy to perform in a flexible and efficient way. Furthermore there are currently no assessment means adapted for complex architectures design in particular during preliminary phase.

Therefore, new innovative processes and associated tools are studied and developped within the project FP7 TOICA. For this, Dassault Aviation and Liebherr Aerospace Toulouse have choosen to rely, as much as possible, on standards (Modelica, FMI, SysML ...). The following paragraphs will detail analysis needs, and process and tools developped using particularly Modelica and FMI.

\section{Analysis of the global design process}

To really understand the benefits of the new process improvements, the current design process, workflows and involved actors will be explained.

\subsection{Current Design process workflow}

The figure below (fig.4) tries to illustrate workflows and traceability links between the different tasks carried out during the design of the vehicle systems by Aircraft systems integrator.

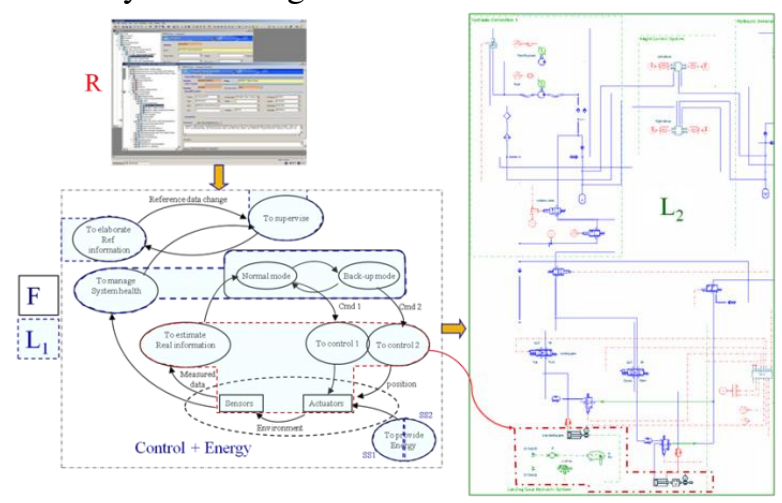

Figure 4. Design process workflow

From the top level requirements $(\mathrm{R})$ are established the aircraft functional analysis which define functions (F) to be performed by the system, and that will be fulfilled by parts of it, sub-systems and components (e.i. equipments ...) These functions are then grouped together to be assigned to sub-systems (L1 view in fig.4), and then to partners as packages called "Product Packages". Partners will then provide solutions implementing the required functions (L2 view).

\subsubsection{Design phases}

The works illustrated above vary along the time from Preliminary system design to detailed Component development. They are developed within next paragraphs regarding design phases.

\subsubsection{Preliminary Design}

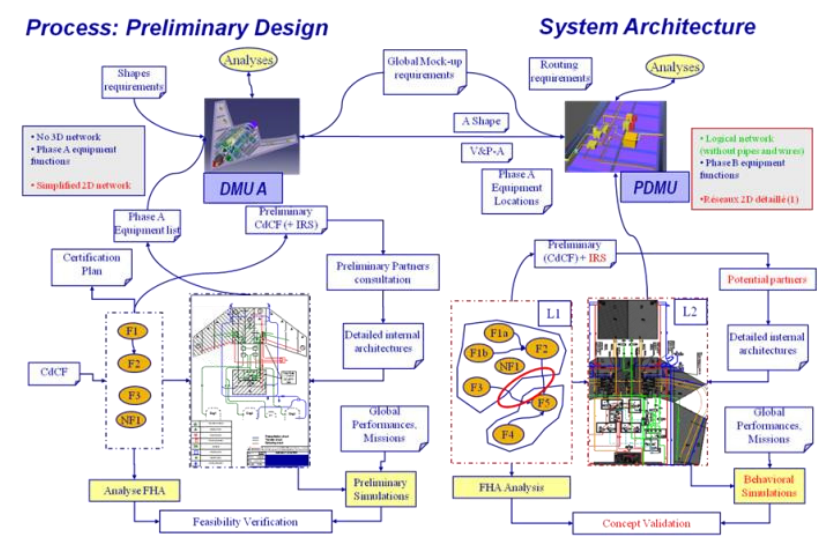

Figure 5. Process regarding Preliminary Design and System Architecture phases (1/2) 
As illustrated above (fig.5), during the Preliminary Design phase of a new Aircraft, a simplified DMU (Digital Mock Up), often parametric, is set-up. And from the preliminary functional requirements, the main functions are defined.

At that point, first global architectures are defined and evaluated. For this, consultation of potential partners is made during the RFI (Request For Information) and RFP (Request For Proposal) phases.

For the preliminary global architecture assessments, different activities can be carried out:

- From the functions, it is possible to make preliminary analysis such as a FHA (Functional Hazard Analysis)

- From the logical architecture, overall performance, missions, operational scenarios, it is possible to make behavioral assessments, reliability and availability estimates. This is currently based on Dassault Aviation models and a few available information provided by partners that are not yet been selected. In this evaluation phase, there will be a clear advantage of being able to use more detailed models from potential partners.

- Other analyses are made in parallel, in particular to define the aerodynamic shape of the aircraft.

\subsubsection{System architecture selection}

During system architecture selection, a preliminary DMU is used to make several types of analysis like engine burst analysis or space allocation.

Functions are refined and preliminary interfaces are assigned among potential Product Packages through ICD (Interface Control Documents).

\subsubsection{Component specification}

During Development Phase, partners have been selected. It is now possible to ask them detailed information on their solution(s), and models to be evaluated in a more global and multi-systems context.

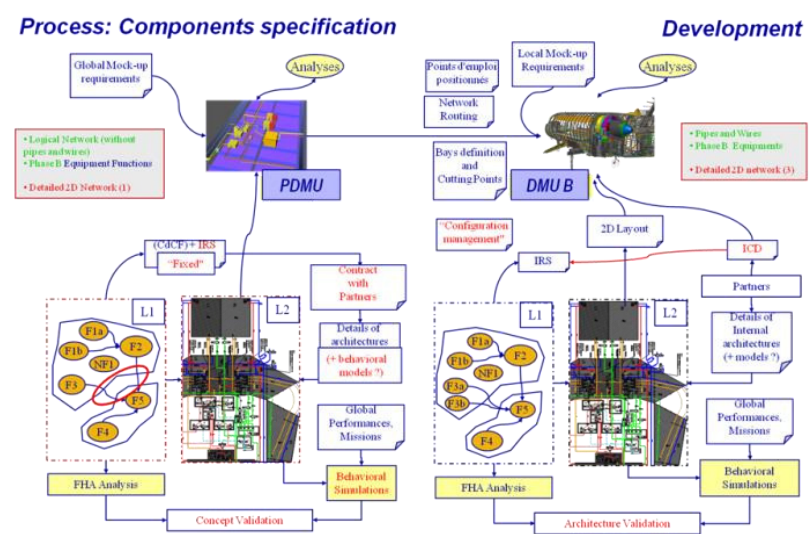

Figure 6. Process regarding Preliminary Design ad System Architecture phases (2/2)

\subsubsection{Development}

During development phases a detailed DMU is set-up and becomes the main reference to build the aircraft. It is fixed when all detailed sub-systems are defined with sufficient details and all Critical Design Reviews passed.

\subsection{Actors}

Many actors take part to the aircraft design. They are in charge of different roles and are allowed to see and interact on subsets of the whole aircraft definition. Figure 7 shows some of the actors involved in TOICA project.

\begin{tabular}{|c|c|c|c|}
\hline \multicolumn{2}{|c|}{ Actors } & Name & Role : In charge of \\
\hline $\begin{array}{l}\text { Aircraft } \\
\text { architect }\end{array}$ & & DASSAV & $\begin{array}{l}\text { Aircraft Architecture: } \\
\text { - Launch trade-off } \\
\text { - Lead Collaborative Design Reviews for the whole Aircraft }\end{array}$ \\
\hline $\begin{array}{l}\text { Multi- } \\
\text { Systems } \\
\text { Architect }\end{array}$ & 8 & DASSAV & $\begin{array}{l}\text { Multi-Systems (Energy) Architecture : } \\
\text { - Definition, validation of Energy systems }\end{array}$ \\
\hline $\begin{array}{l}\text { Thermal } \\
\text { Experts }\end{array}$ & & DASSAV & $\begin{array}{l}\text { Air-Conditioning systems: } \\
\text {-Definition, development and justification }\end{array}$ \\
\hline $\begin{array}{l}\text { Anti-lcing } \\
\text { Experts }\end{array}$ & & DASSAV & $\begin{array}{l}\text { Anti-lcing system: } \\
\text {-Definition, development and justification; in partnership with } \\
\text { Thermal Experts }\end{array}$ \\
\hline $\begin{array}{l}\text { Process And } \\
\text { Tools } \\
\text { Expert(s) }\end{array}$ & & DASSAV & $\begin{array}{l}\text { Process and Tools for Modeling \& simulations: } \\
\text {-Provide Tools and Process for M\&s } \\
\text { - Manage models repository }\end{array}$ \\
\hline $\begin{array}{l}\text { CAE } \\
\text { Analyst(s) }\end{array}$ & & DASSAV & $\begin{array}{l}\text { CAE expert (CFD, FEA): } \\
\text {-CFD calculations } \\
\text { - Models reductions }\end{array}$ \\
\hline $\begin{array}{l}\text { Partners } \\
\text { Thermal } \\
\text { Experts }\end{array}$ & 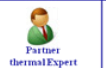 & LTS & $\begin{array}{l}\text { Partner Representative: } \\
\text { - Process and Tools Expert/ Thermal Expert } \\
\text { - Provide sub-systems models }\end{array}$ \\
\hline
\end{tabular}

Figure 7. Actors of Dassault Aviation-LTS use case

\subsection{Managing alternatives}

During early phases, there is a need to manage alternative architectures. Starting from a high level Functional representation, sub-level functions can be grouped together in different ways. Architects and design experts will select different candidate architecture according to overall needs, and solutions provided by potential partners.

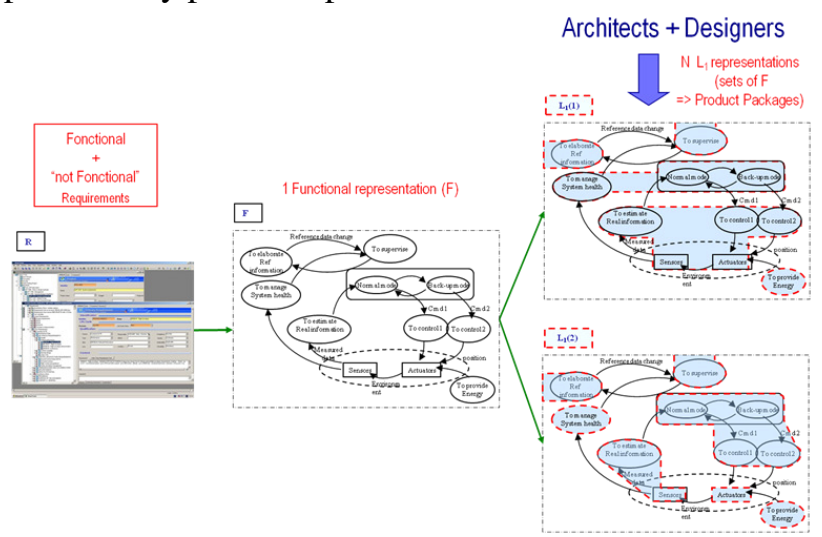

Figure 8. Process and management of alternatives

There are thus several possible Functional representations during early phases which gather sets of functions. But functions don't implement all the requirements. The Non Functional requirements like constraints must not be forgotten, and they must be allocated to the sets of functional requirements as illustrated in fig. 9 below. 


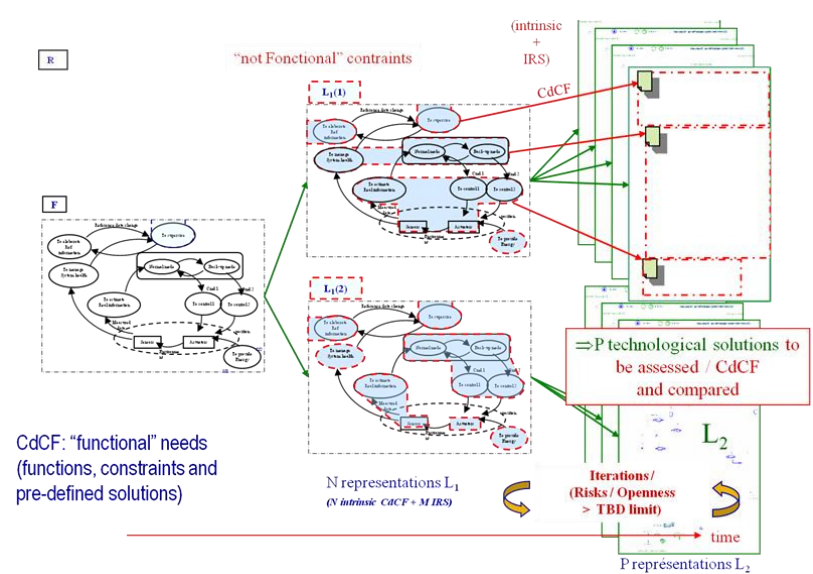

Figure 9. Process and analyses for architecture assessments

Note that openness on sub-systems requirements left to partners should allow them to propose more innovative solutions. But the larger the aperture is, the greater the industrial or contractual risk may be.

\subsection{Multi-systems simulation}

In TOICA, one of the purposes is to investigate more formal exchange by models to allow assessments not only limited to sub-system, but for an overall analysis at multi-systems level (air system, including other boundary systems) and at aircraft level.

For this, models involved in DASSAV-LTS TOICA use-case are defined just below.

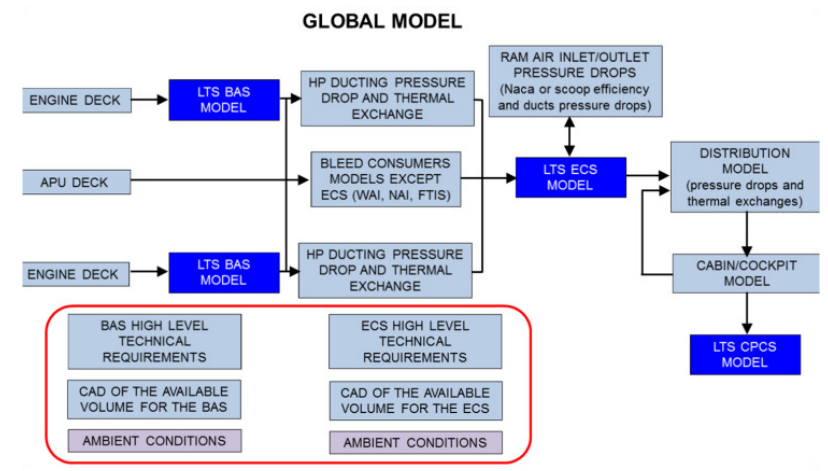

Figure 10. RFI phase models

We can note that partner's subsystems can be highly scattered among the whole system.

The associated architecture could be also defined as below in a SysML (OMG) format:

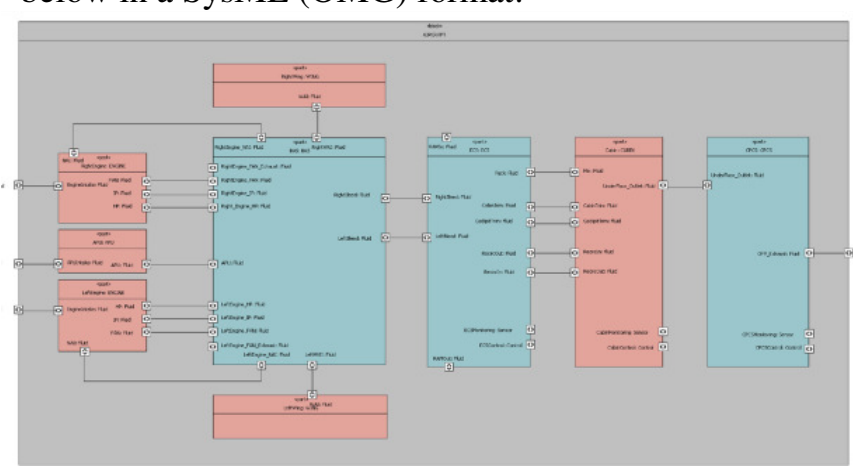

Figure 11. IBD with LTS systems in blue

\section{Enhanced process definition}

\subsection{Introduction}

\subsubsection{Current process}

To be able to make multi-systems assessment, the aircraft systems integrators generally ask for models to system designers. But when trying to build the global simulation, problems often occur when connecting or during simulation of the coupled models. The interfaces don't match as wished, simulations are much slower as expected, models don't publish all expected variables... according to real needs that are not all known at the beginning of the system development ... The process requires more efficiency and flexibility.

\subsubsection{New process}

The primary purpose is to give to the potential partners the capability to check the ability of their models to run efficiently in the Dassault Aviation simulation framework. An additional target is to allow quicker design iterations between Dassault Aviation and partners to test more solutions and potentially more innovative ones.

In TOICA, the foreseen solution is then to provide to potential partners a simulation framework allowing them to carry out previous tasks. This new process of exchange and use of interfaces values and requirements by models in a common framework will ensure a better flexibility, efficiency and traceability.

The Dassault Aviation framework and rules to use it are detailed in next paragraphs.

\subsection{Analyze of current design process.}

The current process between Aircraft manufacturer (Dassault Aviation) and partners (here LTS) at RFI / RFP phase is analyzed. It is illustrated in the following figures, as the workflow from the technical specification provided by Dassault Aviation to partner selection, and for two activities:

- Modification of technical specifications

- Modification of a sub-system such as an ECS (Environmental Control System) pack

\subsubsection{Modification of Technical specification}

The workflow is defined in fig 12. If Aircraft manufacturer wants to modify one or several technical requirements, the new issue must be send to the partners to calculate the impacts on their systems.

Partner's results have to be sent to the Aircraft manufacturer. Then aircraft architects analyze impacts to decide:

- to request partners a system modification or redesign

- to modify the specification to decrease the impacts (e.g. a new calculation loop with partners is needed) 
With this process, iterations between Aircraft manufacturer and partners are required for any modifications of specifications. It requires many sequential tasks which take times to fulfill all the technical specification items.

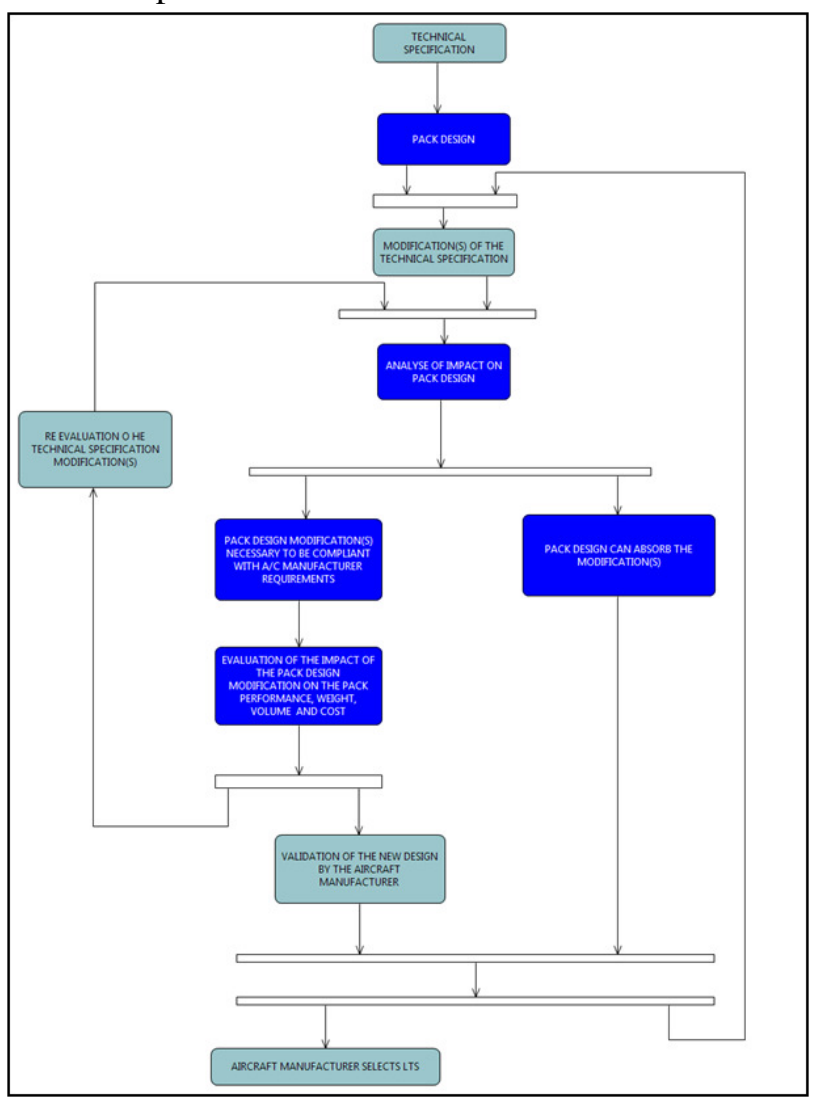

Figure 12. Current design workflow

\subsection{Modified design process}

The new workflow, sketched in fig.13, uses exchange of models. As it will be described in the following paragraphs, all needed models to make systems assessments will be available at Aircraft manufacturer and at other potential partner's offices. Therefore, it allows them to work in parallel.

It enables Aircraft manufacturer to partially evaluate the impacts of these modifications on the partners systems.

Aircraft architects will be able to quickly analyze modification impacts and to decide:

- To request partners some system modifications or redesign

- To adapt the specification to improve the Aircraft without partners system modifications

Then, calculations results and specifications modifications will be sent to partners for validation.

Therefore iterations between Aircraft manufacturer and partners (LTS and other competitors) are reduced and the Aircraft architect can evaluate in a shorter time the impacts of the proposed modification. Aircraft architect will be able to evaluate and adapt the impacts of modifications without iterating with partners.

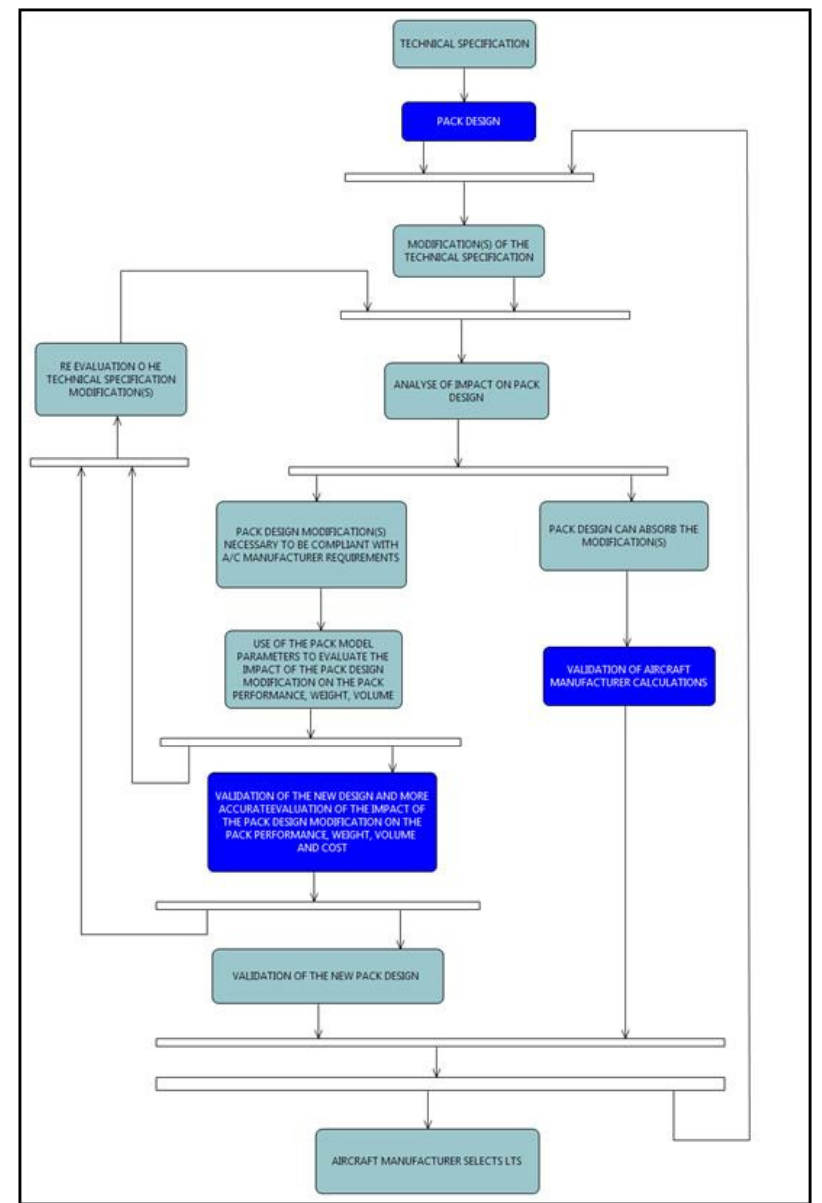

Figure 13. New process

Models exchanges enable partners to evaluate the impacts of system component modification on the aircraft before proposing it to Aircraft manufacturer.

The Integrated Air Management System (IAMS) engineer will be able to evaluate and adapt the impacts of IAMS components design without iterating with Aircraft integrator.

\subsection{Modification of sub-system}

For a sub-system design modification (i.e. ECS Pack) similar advantages could be pointed out as figured out in the following fig.14 (but not detailed in this paper).
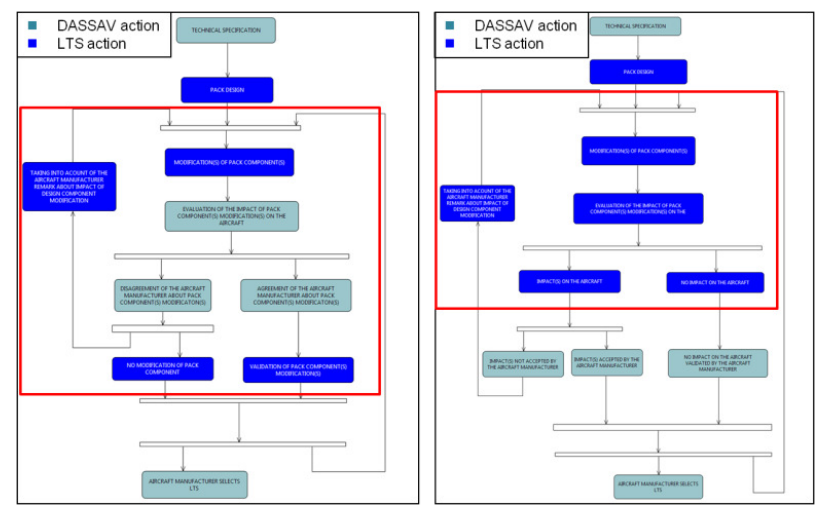

Figure 14. Comparaison between the two process 


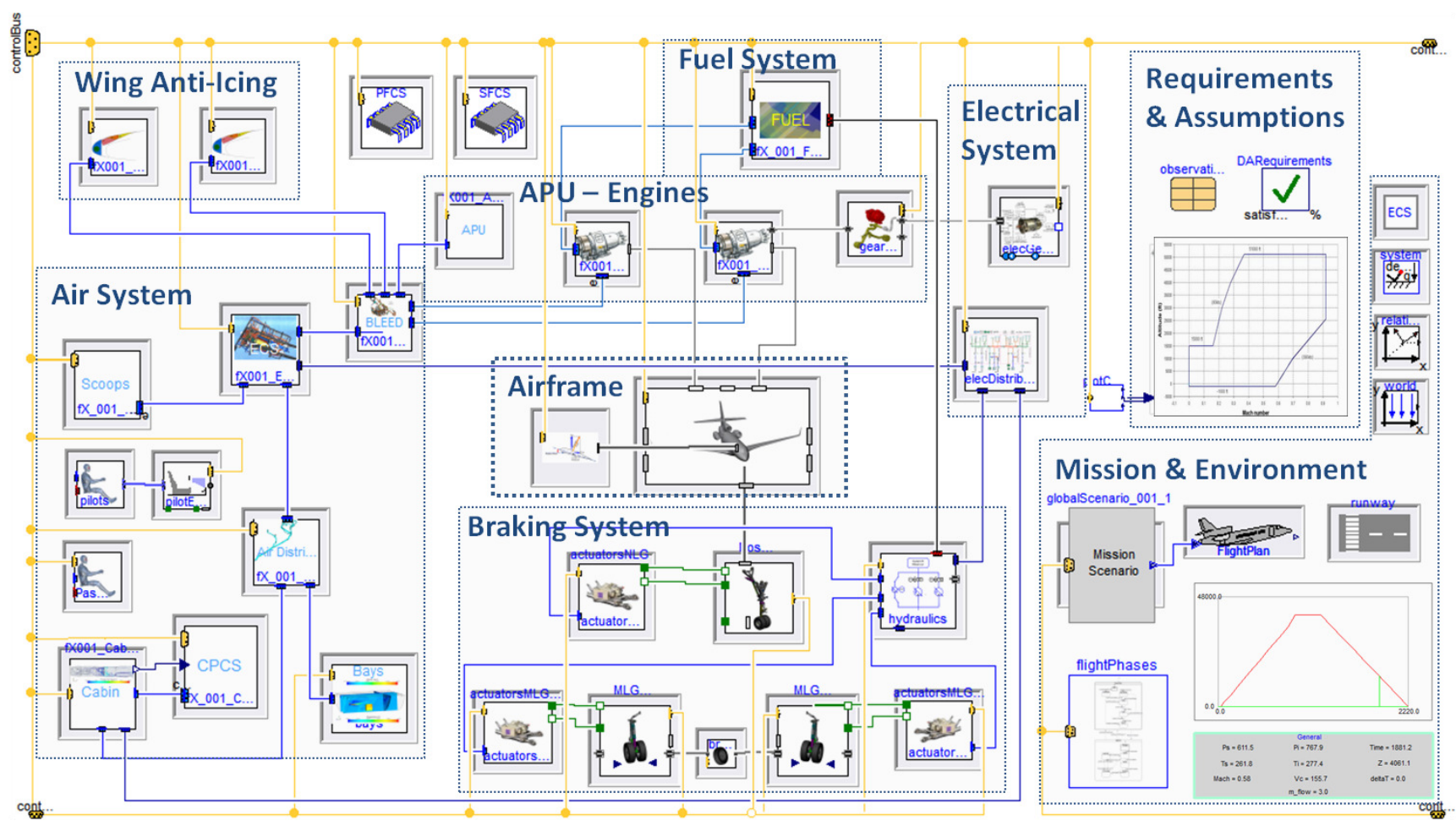

Figure 15. Flat representation of a set of inter-connected systems of a traditional Aircraft Vehicle systems architecture

\section{Solution to set up the new process}

The purpose is to allow an easy connections between models, checking of simulation capabilities as early as possible (within partner's office), before final check and integration within Dassault Aviation global model. The current solution is to provide model Interfaces, boundary models, Mission and test cases to partners. The solution has been defined and implemented as an encrypted Modelica/Dymola library to protect IP (Intellectual Property). It contains the different elements described below:

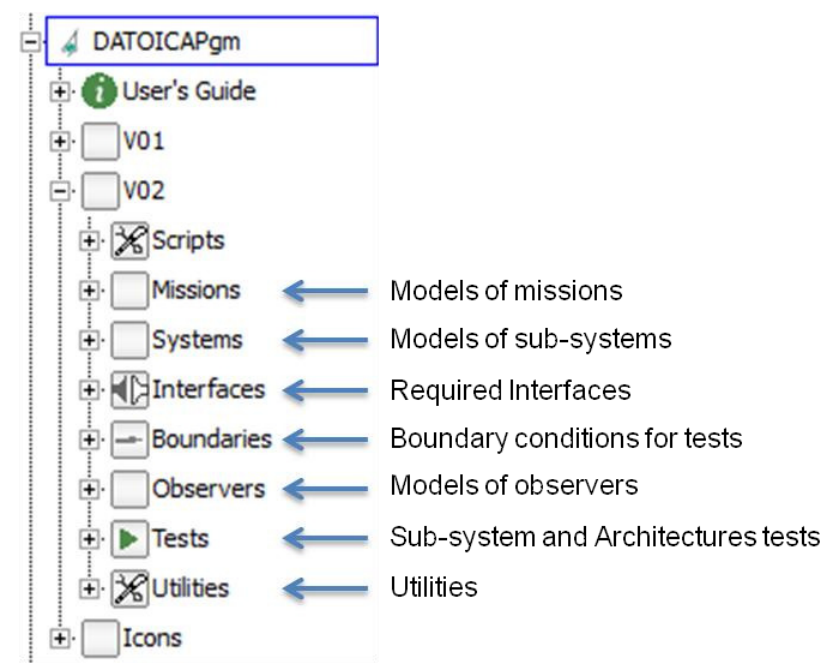

Figure 16. Library content
Note that before encryption, which is specific to Dymola, all components of the library, including protection annotations, are standard Modelica (currently according to Modelica Specification issue 3.3).

\subsection{Components of the library}

The library is mainly composed of models of missions, sub-systems and tests to allow architectures evaluations, and also interfaces to integrate partner's models. Fig. 38, at the end of the paper, shows more details on the current library content.

The following paragraphs describe the major elements and the philosophy of the library.

\subsubsection{Principles}

The library takes advantage of principles used within the Modelica VehicleInterface library described particularly within (M. Dempsey et al, 2006). The VehicleInterface library, dedicated to automotive systems and architectures, was derived by Dassault Aviation for use with Aircraft Vehicle Systems during ITEA2 EUROSYSLIB project. A traditional Aircraft Vehicle systems architecture, extract from this library, is represented in fig.15. It represents the main interconnected elements of such architecture as replaceable components, contrained by predefined interface. All components are also linked together with Simulation Control bus in charge of propagation of information 
from the controlers and from the Mission and Environement models.

At the bottom right are environment components which contain global parameters and models that can be used by any other components using the Modelica inner/outer mechanims. In these parts are represented the World and Fluid system components of the MSL, and other components dedicated to aircraft environment (FlightPlan, Runway, RelativeWorld ...) but also other components with global domain specific parameters and models (ECS, Braking system, Fuel system...) Note that contrary to the Vehicle Interface library where all connectors are single MSL components, the physical connectors have been replaced by composite connectors to limit the number of connections between sub-systems, and to allow a better flexibility when change of interface definitions.

\subsubsection{Examples of elements: Mission Scenario}

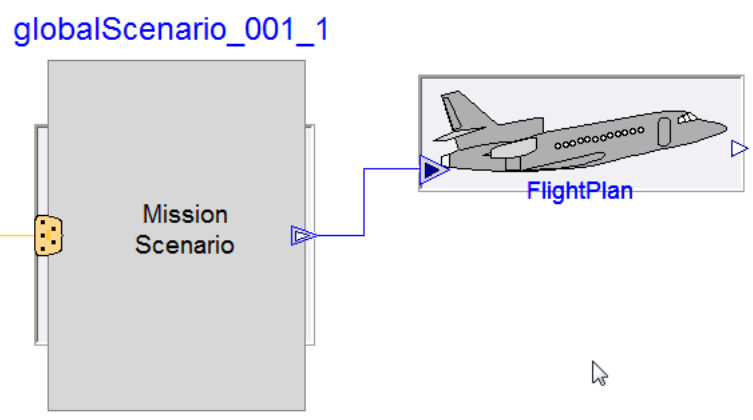

Figure 17. Mission and FlightPlan component icons

The Mission component is a key element of the global model. It provides all information about the predefined aircraft mission scenarios. It may define dynamic scenarios with some information varying along time as represented in the following figures.

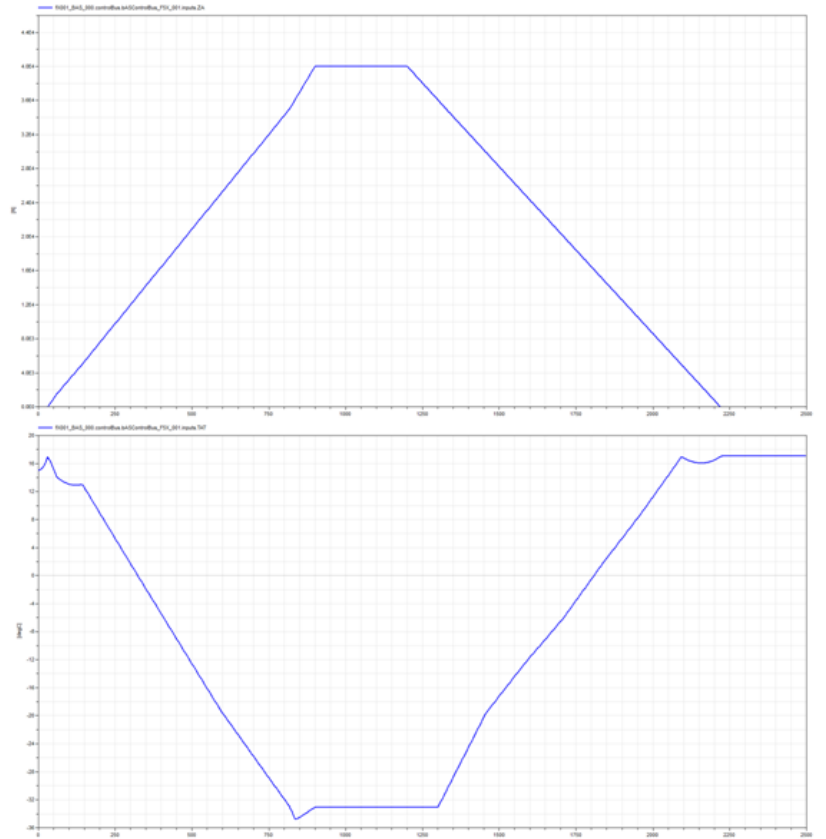

Figure 18. Plots of Aircraft altitude and external stagnation temperature
It is also simple to define stationary scenario if needed with constant outputs. Within the information provided by the Mission components, some information generally depend only on flight phases or are constant along time. There are then defined within the Mission component through graphical user interfaces such as represented in fig. 19.

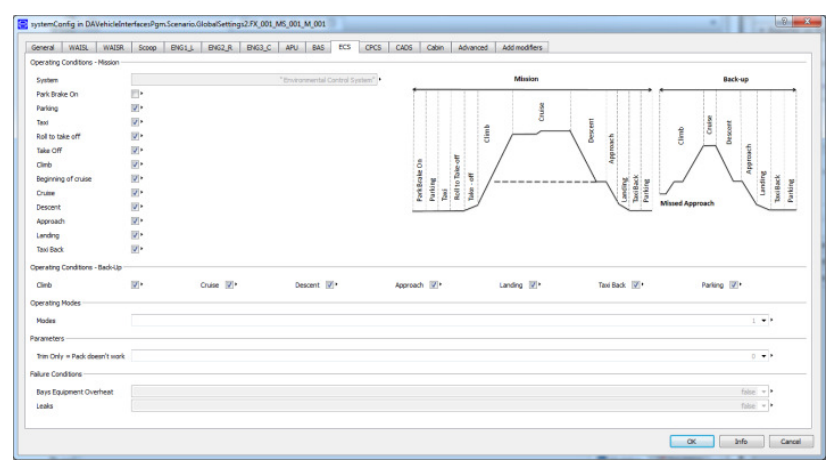

Figure 19. Configuration parameters for the ECS

The Mission model is connected to the FlightPlan component which provides all consistent information on Aircraft properties and associated external variables (altitude, attitude, velocity, Mach number, Temperatures, Pressures, Humidity ...) which must often be known by models of sub-systems.

\begin{tabular}{|c|c|c|c|c|c|}
\hline \multicolumn{6}{|c|}{\begin{tabular}{|l|l|l|l|} 
回 FlightPlan in Tests.test_FX_001_Bus_FocusOn_BAS_ECS_MS_G4DRY_001_... & ? & $\times$ \\
\end{tabular}} \\
\hline General & Tables & Advanced & Visu & \multicolumn{2}{|l|}{ Add modifiers } \\
\hline \multicolumn{6}{|c|}{ Definitions - } \\
\hline \multicolumn{4}{|c|}{ altitude unit choice } & $\mathrm{ft}$ & • \\
\hline \multicolumn{4}{|c|}{ altitudes ( $m$ or feet) vs time } & \multicolumn{2}{|c|}{$[0,0 ; 1,0]$ 国 } \\
\hline \multicolumn{4}{|c|}{ speed description choice } & (-) Mach $\bigcirc \mathrm{Vc}$ & ' \\
\hline Vc (kt) o & Mach $(-)$ & time & & \multicolumn{2}{|c|}{$[0,0 ; 1,0]$ 国 } \\
\hline \multicolumn{6}{|c|}{ Atitude Definitions - } \\
\hline \multicolumn{4}{|c|}{ use fixed pitch } & \multicolumn{2}{|c|}{ false $\rightarrow$, } \\
\hline \multicolumn{4}{|c|}{ fixed pitch } & \multicolumn{2}{|c|}{ 0. deg } \\
\hline \multicolumn{4}{|c|}{ pitchs $\left(\hat{A}{ }^{\circ}\right)$ vs time } & \multicolumn{2}{|c|}{$[0,0 ; 1,0]\left[\begin{array}{l} \\
\end{array}\right.$} \\
\hline
\end{tabular}

Figure 20. Part of GUI of the FlightPlan model

The mission model may recover information from sensors or from the different sub-systems models. Among them, Aircraft phases are modeled by a Modelica state diagram (Modelica synchronous), such as the one represented in the following figure.

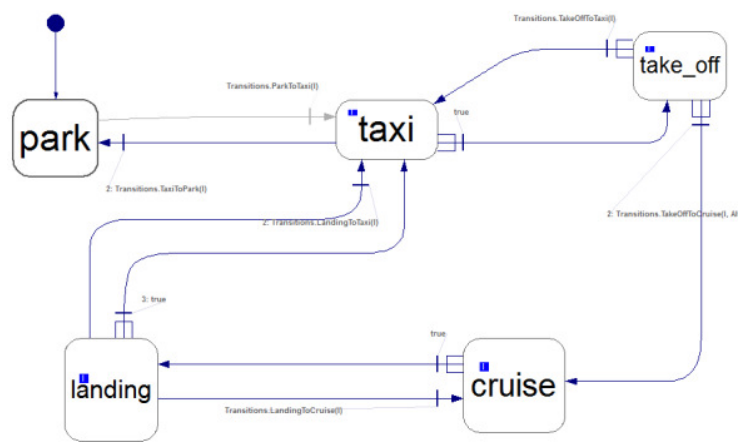

Figure 21. Simple Flight phases model 


\subsubsection{Examples of sub-system models: cabin}

The cabin and cockpit may be modeled with different level of details. For the RFI/RFP phases, where still few detailed information are available, some simple models as represented below may be sufficient. In this model, crew and passengers (Pax) areas are represented by only big thermo-fluid volumes externally connected to other sub-systems.

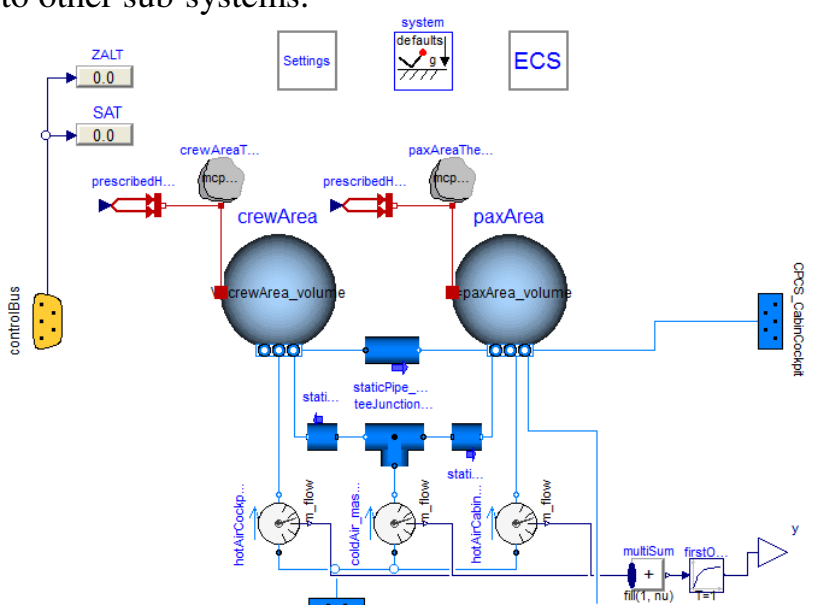

Figure 22. Simple model for Cockpit and Cabin

Heat exchanges are modeled by prescribed heat flows according to relation that here depends only on the number of crew members and passengers and the different other heat sources within the volumes and exchange with boundaries. These heat exchanges are here defined by parameters related to aircraft altitude (ZALT) and external static temperature (SAT). These two input parameters are provided by the Mission component through the simulation control bus.

Parameters can be set manually by users. Here below is presented the graphical user interface available for the partners, that allows them to change parameters if needed.

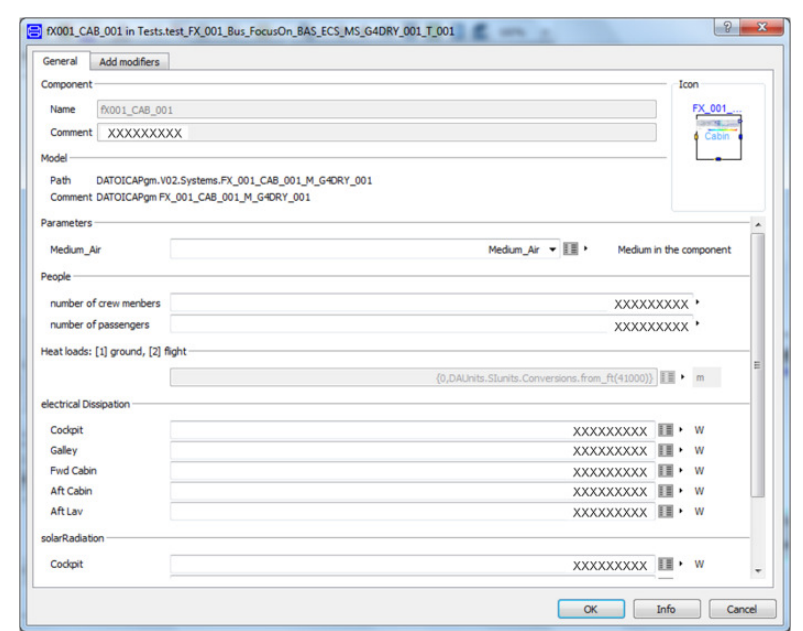

Figure 23. Cabin parameters available for Partners

In fact this component is also available at Aircraft integrator facility, with more published parameters.

\subsection{Library usage}

Currently, systems requirements for performance assessment, asked to partners, are provided as textual format.

One of the purposes of the library is to provide more formal requirements, as models, and tests that must be completed by partners to verify the compatibility of their solutions with requirements. They are the translation in models of current textual requirements.

Below are presented scenario and checks that should help checks of partner's systems.

\subsubsection{Global scenarios assessment}

Within the Tests packages, are provided tests of subsystems and more global models for architecture assessments of partner sub-systems. In this case, the ECS and BAS (Bleed Air System) are sub-systems which should be developed by partners. BAS provides air from engines to different direct consumers like ECS and WAIS (Wing Anti-Icing System).

Predefined scenarios are presented in the library Tests package, as shows in fig. 24 .

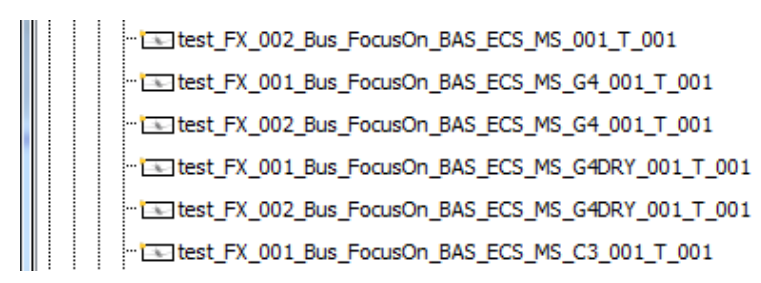

Figure 24. Set of models for architecture assessment

Such a predefined scenario is represented in the following figure. This part of the global architecture is limited to BAS and ECS that should be developed by partners (LTS ...) and to the boundary sub-systems, provided by the Aircraft Integrator as models.

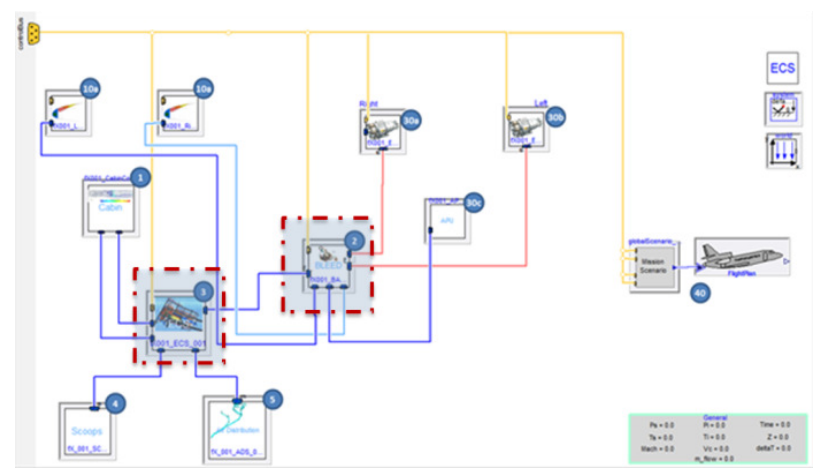

Figure 25 Architecture FX_001 focus on BAS ans ECS

Elements of the model:

- (40): Scenario (Mission) and environment

- (2): Bleed Air System (BAS)

- (3): Environmental Control System (ECS)

- (30a et 30b): Propulsion System (Engines)

- $\quad(10 \mathrm{a}$ et $10 \mathrm{~b})$ : Wing Anti-Icing System (WAIS)

- (1a et 1b): Cabin and Cockpit

- (4): Scoops

- (5): Air Distribution System

- (30c): Auxiliary Power Unit (APU) 


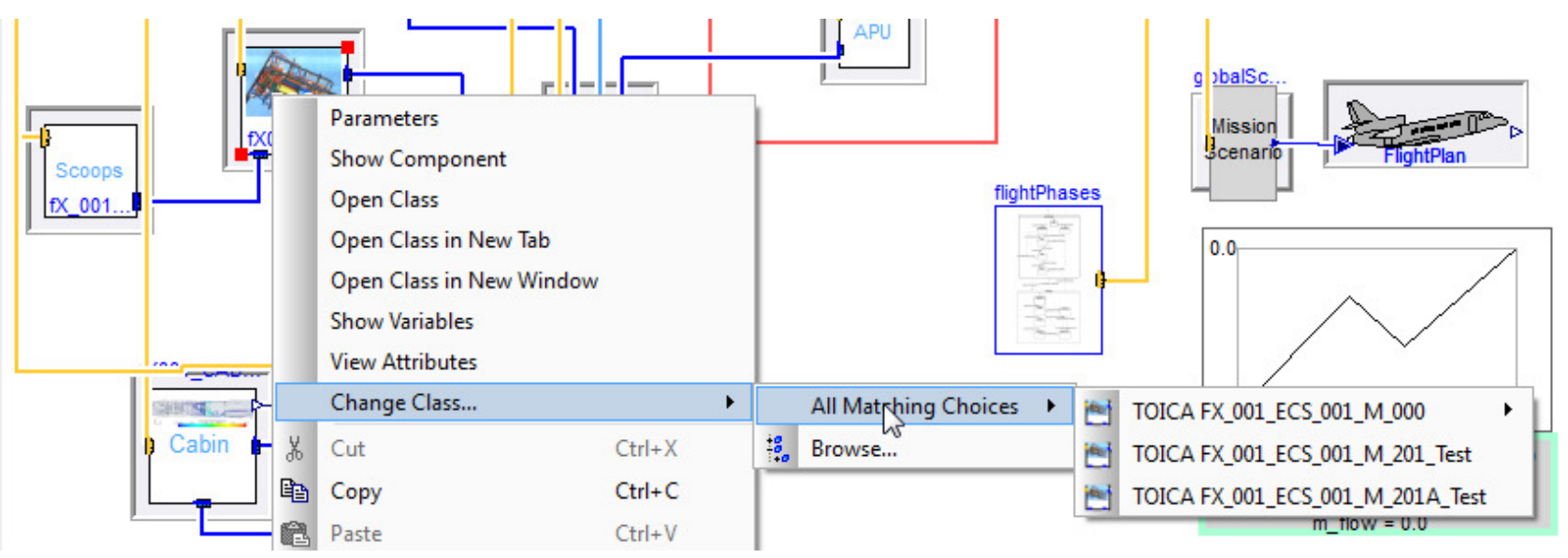

Figure 26. selection among replaceable models constrainted by the predefined interface

The aim of the test cases is to allow the partner to check the behavior of their systems integrated with boundary sub-systems, and adjust them to comply with requirements. The different test cases must be delivered by the partners as part of evidence of the right technical choices made by them.

These test cases are also useful to guaranty that models developed by partners are able to simulate correctly with predefined boundary models, scenario and solver configurations. This may serve as acceptance tests of models at partner's offices, which must give the same results in similar conditions at integrator facility, before final integration.

The models of partners will be used to study the integration of partner sub-systems within the global architecture with the interaction with more detailed models only available at Dassault Aviation, with other sub-systems, or to make trade-offs between different architectures.

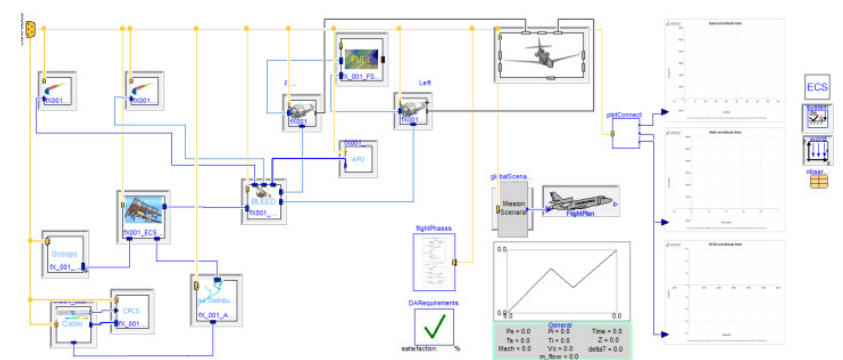

Figure 27. Partners models integrated within Dassault Aviation environment (flat view)

According to analysis needs, partners should provide models of sub-systems with different characteristics, in particular with:

- The integration and connection of their models to predefined interfaces (extended from Interfaces connectors package). See example fig. 28.

- The right level of details to get the right behavior according to the specified analysis (stationary, dynamics ...)
- The required parameters and published variables,

- A clear designation. Each model must be clearly identified like defined in the following table to assure models versioning and traceability.

Table 1 Set of models involved within design.

\begin{tabular}{|l|l|l|l|}
\hline Icon & Interfaces & Variants & Objective \\
\hline & IF_FX_001_CAB_001 & FX_001_CAB_001_M_001 & $\begin{array}{l}\text { Cabin simple } \\
\text { model }\end{array}$ \\
\hline & & Fx_001_CAB_001_M_002 & $\begin{array}{l}\text { Cabin detailed } \\
\text { model }\end{array}$ \\
\cline { 3 - 4 } & & $\begin{array}{l}\text { Cabin detailed } \\
\text { model }\end{array}$ \\
\cline { 3 - 4 } & & Fx_001_CAB_001_M_003 & \\
\hline
\end{tabular}

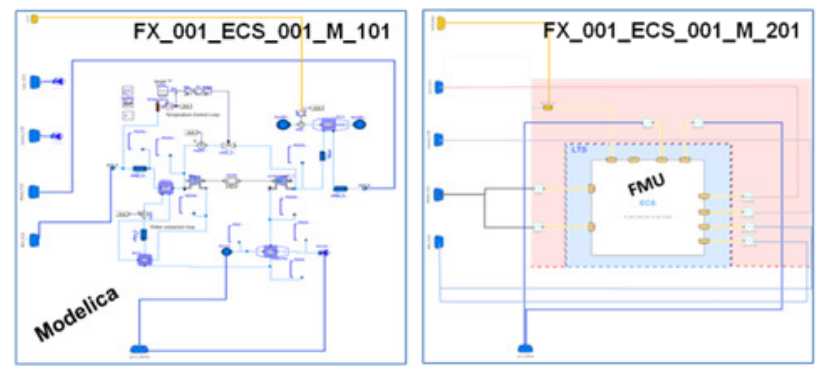

Figure 28 Example of models which inherite of the same interface

\subsubsection{Sub-systems checks}

It is required to provide models as Modelica models or FMU embedded within Modelica.

The purpose of using Modelica and FMU is to use standards. It is then important to be able to check that Modelica models and/or FMUs are in accordance with the specifications. For this, Modelica Association provides tools to check theses compliances.

It is also requested to check each model individually, using at minimum test benches provided in the library, as represented in the following figure. 


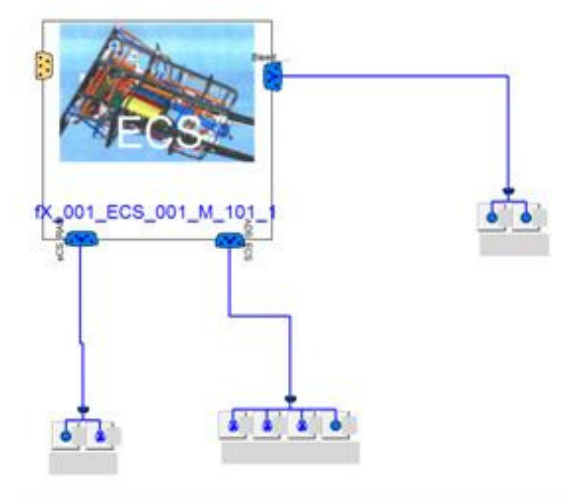

Figure 29 Bounday condition for ECS model.

\subsection{Aircraft systems modeling}

\subsubsection{Aircraft modeling specificities}

Aircraft systems simulations is a very complex activity, mainly due to the wide range of the variable trajectories, the diversity of media and also the complexity coming with trade-offs analysis which require multi system simulations with multi-levels of details.

In Table 2, are listed some physical / thermodynamical variable ranges in such systems.

Table 2 Ranges for variables in fluid circuits

\begin{tabular}{|c|c|c|c|c|}
\hline 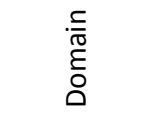 & $\begin{array}{l}\frac{0}{0} \\
\frac{\sqrt{0}}{\frac{10}{50}} \\
\frac{10}{3}\end{array}$ &.$\subseteq \frac{\varrho}{\xi}$ & $\begin{array}{l}\stackrel{\times}{\mathbb{E}} \\
\varepsilon\end{array}$ & 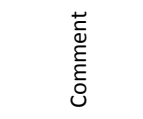 \\
\hline \multirow{3}{*}{ Air System } & $\mathrm{T}$ & $-100^{\circ} \mathrm{C}$ & $+700^{\circ} \mathrm{C}$ & \multirow{5}{*}{$\begin{array}{l}\text { Thermal- } \\
\text { pneumatics }\end{array}$} \\
\hline & $\mathrm{P}$ & $0 \mathrm{mbar}$ & 50 bar & \\
\hline & $\mathrm{H}$ & $0 \%$ & $100 \%$ & \\
\hline \multirow{2}{*}{ Pneumatics } & $\mathrm{T}$ & $70 \mathrm{~K}$ & $400 \mathrm{~K}$ & \\
\hline & $P$ & 0 bar & $600 \mathrm{bar}$ & \\
\hline \multirow[t]{2}{*}{ Fuel System } & $\mathrm{T}$ & $\begin{array}{l}-40^{\circ} \mathrm{C} / \\
\left(-55^{\circ} \mathrm{C}\right)\end{array}$ & $+70^{\circ} \mathrm{C}\left(+120^{\circ} \mathrm{C}\right)$ & \multirow{4}{*}{$\begin{array}{l}\text { Thermal } \\
\text { Hydraulics }\end{array}$} \\
\hline & $P$ & 0 bar & 6 bar & \\
\hline \multirow{2}{*}{ Hydraulics } & $\mathrm{T}$ & $-40^{\circ} \mathrm{C}$ & $+125^{\circ} \mathrm{C}$ & \\
\hline & $P$ & 0 bar & 500 bar & \\
\hline
\end{tabular}

Up to recently, traditional commercial tools generally failed to solve such mathematical models. Companies like LTS or Dassault Aviation have then built their own tools (respectively EOLE and FAST for steady-state assessments of air systems) or set of dedicated tools to tackle the problem; but with difficulties during initialization or convergence of solvers.

For several years, Dassault Aviation and LTS have been working to improve the situation, and came to test and then use Modelica for physical system and some control system modeling; and FMI for exchange of models with IP management. Dassault Aviation started tests during the project ITEA2 EUROSYSLIB, which brought some Modelica libraries applicable for aircraft systems simulation (T. Vahlenkamp et al, 2009; F. Casella et al, 2009). But still with some restrictions of use, so that complementary developments has been carried out to try to lessen limitations. Nevertheless, after several years of improvements of models, process and tools, it is now possible to expect being able to make multi-system simulations. In parallel, LTS has worked during Cleansky with TUHH and owns now multi-level models for fluid and control systems simulations (P. Jordan et al, 2014), and in addition process to speed up simulation by using surrogate models.

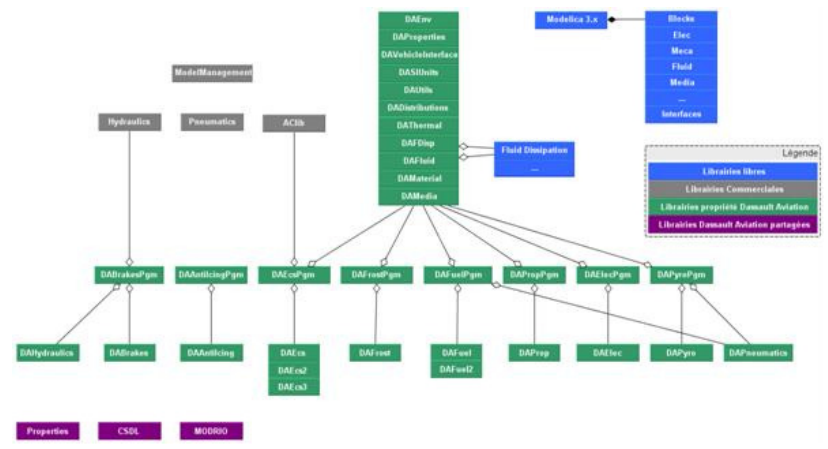

Figure 30 Set of Modelica libraries used at Dassault Aviation

\subsubsection{Choice of tool}

The integration tool during RFI/RFP phases could be either Dymola or V6 DBM (Dymola Behavior Modeling, which is integration of Dymola within the Dassault Systèmes 3DExperience platform Catia V6) depending on the needs. Until partner selection, it is necessary that the tool that will run the models at partner's office could be easily integrated within partner IT simulation network. If the partner doesn't use yet Catia V6 3DExperience, Dymola seems currently less intrusive. Even if in the future, we could imagine that Dymola workbench could be proposed with remote access reached through a secured network.

\subsubsection{Types of models}

In TOICA, one of the targets is to be able to make architecture trade-offs as close as possible to reality.

Therefore, it involves a set of heterogeneous models made as Modelica libraries (sometimes encrypted), FMUs (sometimes for integration, or co-simulation) like those represented in the following figure.

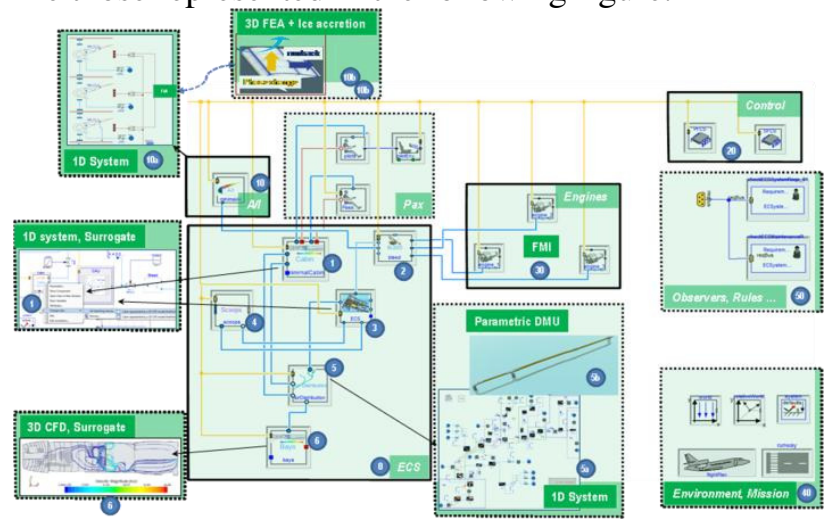

Figure 31 Set of heterogeneous models involved within air system design (TOICA use case) 
Several of these models are surrogate models built from 3D CFD or FEA simulations, which could be embedded either in Modelica or FMU like already done in project CSDL (E. Thomas et al, 2012).

\subsubsection{Problem to tackle}

The remaining problem for simulation of complex model is to get sufficiently quick simulations to be able to make assessments and take decision on time.

Complexity could come from heterogeneity of models, which leads to various dynamic phenomena coupled together. It could also come from Modelica power which allows strong coupling of dynamic physical model to control model with discrete or synchronous features. Finally, it could come from FMU allowing transformation of models as black boxes, which is not always compliant with efficient simulations.

But before simulation, it is required to be able to initialize the models. The convergence of Newton Solver during initialization is a key challenge. It is particularly important for fluid systems which often lead to solve complex non-linear and stiff equations, and numerical oscillations at the beginning of the simulation.

Several strategies have been developed, such as the homotopy method or with some decoupling especially during initial phase.

All these simulation issues tend to find solutions with improvement of Modelica tools and FMU definition. But, it will be also mandatory to be able to check easily that models are compliant with rules or requirements. For this current development within the project ITEA2 MODRIO, and initiated in EUROSYSLIB to observe models and check requirements will help designers.

\section{From early design phase to detailed phase}

\subsection{Introduction}

As soon as partners have been selected following RFP phase, Development phase will surge and architecture definition will continue to grow up to detail solution and bring them to reality. It is then mandatory to use strong process and associated tools to manage subsystems and partners all together and in a consistent way, from top requirements to solutions as illustrated in fig.34. For these activities Dassault Aviation, like other Aircraft integrators, uses PLM environment (Product Lifecycle Management).

The following picture illustrates how can be managed information from an architecture level to another with traceability links from high level requirements to the DMU of the whole aircraft.

Within a previous project, CSDL, the links between requirements and simulation has been already analyzed successfully, but still with few models. The target of
TOICA is to develop the process and tools to enable handling of more complex systems, close to actual aircraft systems.

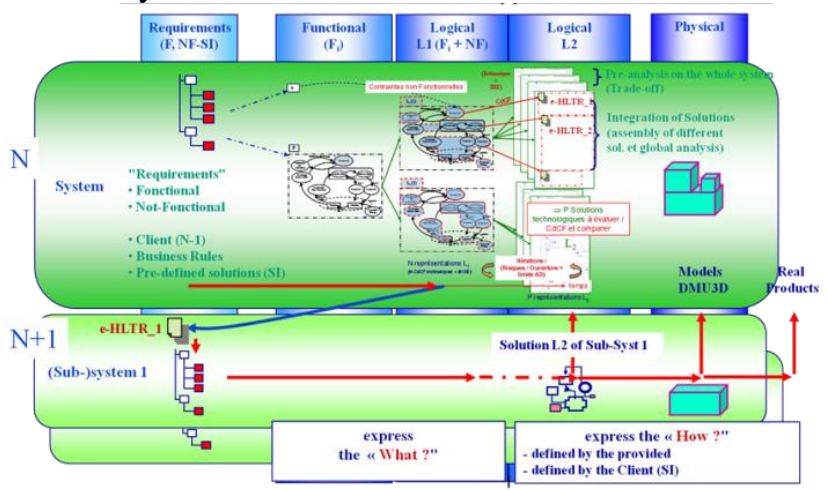

Figure 32. RFLP process and need of systems analyses

\subsection{PLM Integration}

In Toica, one of the investigated major topics is to build up a so called "Architect Cockpit" to help Architects (at Aircraft level, sub-systems levels for managing efficiently alternatives and trade-offs in a collaborative way). The target is in particular to buildup and demonstrate ability to manage in a collaborative context models with multi-levels of details for making trade-offs between architectures, with close operational design.

Dassault-Aviation uses for this purpose the 3D Experience platform from Dassault-Systèmes, which tightly integrates traditional a common 3D Digital Mock-Up (DMU) with system engineering activities, including simulation. In particular it allows managing roles of users, design workplace to work within defined teams or to share information with other partners.

The purpose of this paragraph is to show that the process and tools described before, dedicated to RFI/RFP phases, are fully compatible with the Development design phase, with a progressive and smooth integration.

The architectures hierarchy defined in fig. 1 has been reproduced in Catia Systems, with two alternatives (a traditional alternative, and a More Electrical one). One of the alternatives is represented in the fig.34, with highlight of the Air sub-system.

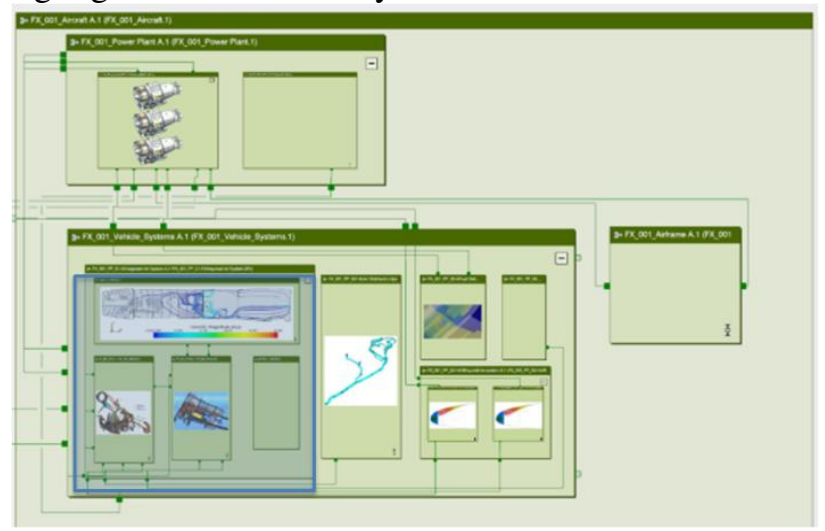

Figure 33. Representation of the traditional Architecture 
As illustrated below, internal models and partner models can be attached to each sub-systems or equipments.

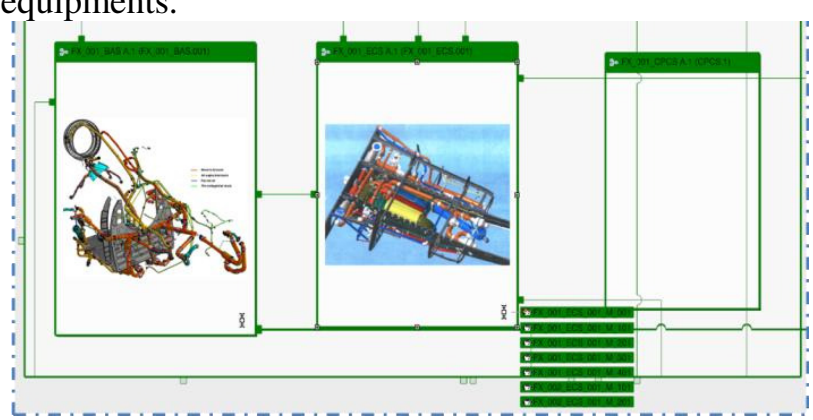

Figure 34. Replaceable models attached to ECS

Associated models, with their interfaces, are integrated within each system as represented below.

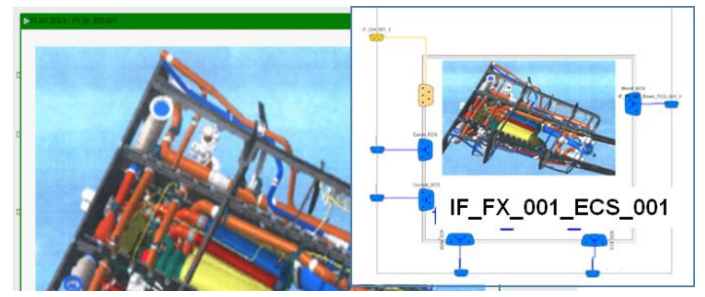

Figure 35. One of the model attached to ECS

Even quickly described above, it can be shown that the models for early phases and development phases are managed in the same repository:

- Dassault Aviation framework, as encrypted Modelica/Dymola libraries, provided to partners can be generated automatically

- Models provided by partners can be quickly added to the models attached to sub-systems in V6 3DExperience platform, and are automatically compatible if partners have integrated then according to required interfaces.

It is then possible to use V6 tools 3DExperience environment to define and manage scenarios for testing subsystems and making trade-offs, which can be recorded in V6 database, to be modified or replayed further as illustrated in (fig.36).

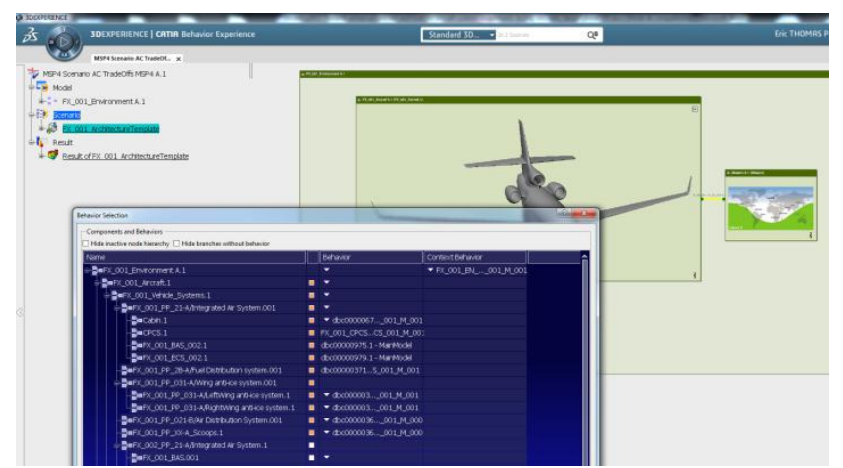

Figure 36. Scenario within V6 3D Experience

\section{Conclusions}

This paper has highlighted needs for aircraft systems design. It has also described the new process being developed within FP7 TOICA project. It brings out solutions to allow easier handling of complex systems assessments in a better and more flexible way.

In the current process, the aircraft architects ask suppliers to provide models for multi-systems assessments into Aircraft integrator office. This process has two drawbacks. It is difficult to assure that models will run in integrator's facility, and this request can't be currently handled efficiently during very early phases like RFI or RFP phases.

The new process, based on model exchanges using a Modelica framework, allow more efficiency and flexibility. As demonstrated, the workflow for architecture and sub-system assessment is straightforward compared to current one. In addition, it may more deeply imply partners in assessment success, and may allow finding more innovative solutions by opening up aircraft requirements.

The process and associated tools are based on current powerful capabilities of Modelica and FMI which continue to improve to be able to manage heterogeneous models required for Aircraft systems assessment.

This paper has also briefly described some elements of the further phases to show that the new process is fully compatible, and takes advantage of tools associated, to development phases.

\section{Acknowledgements}

This work was partially supported by the French government through the FP7 TOICA (Thermal Overall Integrated Conception of Aircraft) and ITEA2 MODRIO (Model Driven Physical Systems Operation) projects.

\section{References}

Martin Malmheden, Jean-Baptiste Quincy, Michel Ravachol, Eric Thomas. "CSDL - Collaborative complex system design applied to an aircraft system". Modelica Conference, No 9, pp. 855-865, 2012. DOI: 10.3384/ecp12076855

Mike Dempsey, Magnus Gäfvert, Peter Harman, Christian Kral, Martin Otter, Peter Treffinger. "Coordinated automotive libraries for vehicle system modeling" Modelica Conference, No 5, pp. 33-41, 2006.

Gertjan Looye. "The New DLR Flight Dynamics Library" Modelica Conference, No 6, pp. 193-2012, 2008

Philip Jordan, Gerhard Schmitz. “A Modelica Library for Scalable Modeling of Aircraft Environmental Control Systems". Modelica Conference, No 10, pp. 599-608, 2014. DOI: 10.3384/ECP14096599

Bettina Oehler. "Modeling and Simulation of Global Thermal and Fluid Effects in an Aircraft Fuselage". Modelica Conference, No 4, pp. 497-506, 2005. 
Thorben Vahlenkamp, Stefan Wischhusen "FluidDissipation for Applications - A Library for Modelling of Heat Transfer and Pressure Loss in Energy Systems". Modelica Conference, No 7, pp. 132-141, 2009. DOI: 10.3384/ecp09430012

Francesco Casella, Hilding Elmqvist, Rüdiger Franke, Sven Erik Mattson, Hans Olsson, Martin Otter, Michael Sielemann "Stream Connectors - An Extension of Modelica for Device-Oriented Modeling of Convective Transport Phenomena". Modelica Conference, No 7, pp. 108-121, 2009. DOI: 10.3384/ecp09430078

Francesco Casella, Rüdiger Franke, Katrin Proelss, Martin Otter, Michael Sielemann, Michael Wetter "Standardization of Thermo-Fluid Modeling in Modelica.Fluid". Modelica Conference, No 7, pp. 108121, 2009. DOI: 10.3384/ecp09430077

Michael Wetter "Modelica Library for Building Heating, Ventilation and Air-Conditioning Systems". Modelica Conference, No 7, pp. 393-402, 2009. DOI: 10.3384/ecp09430042

Daniel Bouskela, Laurent Chastanet, Audrey Jardin, Sandrine Loembé, Thuy Nguyen, Nancy Ruel, Raphaël Schoenig, Eric Thomas "Modelling of System Properties in a Modelica Framework". Modelica Conference, No 8, pp. 497-506, 2011. DOI: 10.3384/ecp11063579

Martin Otter, Nguyen Thuy, Daniel Bouskela, Lena Buffoni, Hilding Elmqvist, Peter Fritzson, Alfredo Garro, Audrey Jardin, Hans Olsson, Maxime Payelleville, Wladimir Schamai, Eric Thomas and Andrea Tundis "Formal Requirements Modeling for Simulation-Based Verification". Modelica Conference, No 11, 2015.

\section{Websites}

Modelica Association website: www.modelica.org

FMI website: https://fmi-standard.org

ITEA2 EUROSYSLIB project: www.eurosyslib.org

ITEA2 MODELISAR project: www.modelisar.com

FP7 TOICA project: http://www.toica-fp7.eu/

ITEA2 MODRIO project: www.ITEA2.org/ Modrio

OMG SysML: www.omgsysml.org

\section{List of Acronyms / Abbreviations}

\begin{tabular}{|l|l|}
\hline $\begin{array}{l}\text { Acronym / } \\
\text { Abbreviation }\end{array}$ & Definition \\
\hline A/C & Aircraft \\
\hline APU & Auxiliary Power Unit \\
\hline BAS & Bleed Air System \\
\hline CAB & Cabin \\
\hline CAU & Cold Air Unit \\
\hline CPCS & Cabin Pressurization Control System \\
\hline DASSAV & Dassault Aviation abbreviation within TOICA \\
\hline DMU & 3D Digital Mock-Up \\
\hline ECS & Environmental Control System \\
\hline FHA & Functional Hazard Analysis \\
\hline FMI / FMU & Functional Mock-Up Interface / Unit \\
\hline ICD & Interface Control Document \\
\hline IAMS & Integrated Air Management System \\
\hline IP & Internal Property \\
\hline
\end{tabular}

\begin{tabular}{|l|l|}
\hline $\begin{array}{l}\text { Acronym / } \\
\text { Abbreviation }\end{array}$ & Definition \\
\hline LTS & Liebherr Aerospace Toulouse \\
\hline MSL & Modelica Standard Library \\
\hline Pax & Passengers \\
\hline PLM & Product Lifecycle Management \\
\hline RFI / RFP & Request For Information / Proposal \\
\hline WAIS & Wing Anti-Ice System \\
\hline
\end{tabular}

\section{Annexe}

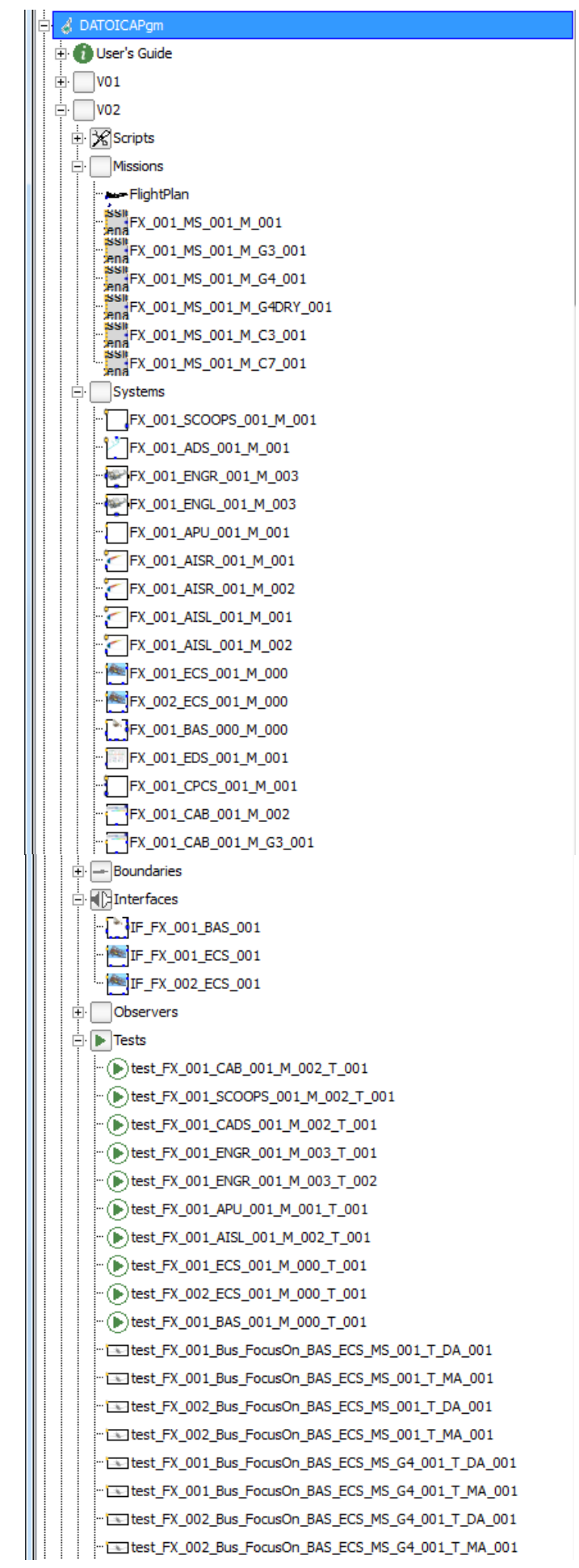

Figure 37. Library content 